\title{
Influence of Solvents' Polarity on the Physicochemical Properties and Photocatalytic Activity of Titania Synthesized Using Deinbollia pinnata Leaves
}

\author{
Yakubu Rufai ${ }^{1,2}$, Sheela Chandren ${ }^{1,3 *}$ and Norazah Basar ${ }^{1}$ \\ ${ }^{1}$ Department of Chemistry, Faculty of Science, Universiti Teknologi Malaysia, Johor Bahru, Malaysia, ${ }^{2}$ Department of \\ Chemistry, Federal College of Education (FCE), Okene, Nigeria, ${ }^{3}$ Centre for Sustainable Nanomaterials, Ibnu Sina Institute for \\ Scientific and Industrial Research, Universiti Teknologi Malaysia, Johor Bahru, Malaysia
}

OPEN ACCESS

Edited by:

Chun Xu,

The University of

Queensland, Australia

Reviewed by:

K. M. Garadkar

Shivaji University, India

Vincenzo Vaiano,

University of Salerno, Italy

*Correspondence:

Sheela Chandren

sheela@utm.my

Specialty section:

This article was submitted to Catalysis and Photocatalysis,

a section of the journal

Frontiers in Chemistry

Received: 23 August 2020 Accepted: 09 November 2020 Published: 03 December 2020

Citation:

Rufai Y, Chandren S and Basar N (2020) Influence of Solvents' Polarity on the Physicochemical Properties and Photocatalytic Activity of Titania Synthesized Using Deinbollia pinnata

Leaves. Front. Chem. 8:597980.

doi: 10.3389/fchem.2020.597980
Nanotechnology is one of the most interesting areas of research due to its flexibility to improve or form new products from nanoparticles (NPs), and as a fast, greener, more eco-friendly and sustainable solution to technological and environmental challenges. Among metal oxides of photocatalytic performance, the use of titania $\left(\mathrm{TiO}_{2}\right)$ as photocatalyst is most popular due to its unique optical and electronic properties. Despite the wide utilization, the synthesis of $\mathrm{TiO}_{2} \mathrm{NPs}$ bears many disadvantages: it utilizes various less environmental-friendly chemicals, high cost, requires high pressure and energy, and potentially hazardous physical and chemical methods. Hence, the development of green synthesis approach with eco-friendly natural products can be used to overcome these adverse effects. In this work, $\mathrm{TiO}_{2} \mathrm{NPs}$ have been prepared by using Deinbollia pinnata leaves extracts, obtained by different solvents ( $n$-hexane, ethyl acetate, and ethanol) with different polarities. The extracts acted as the reducing agent, while titanium isopropoxide as the precursor and water as the solvent. X-ray diffraction (XRD) pattern confirmed the synthesized $\mathrm{TiO}_{2}$ consist of anatase phase in high purity, with average crystallite size in the range of 19-21 nm. Characterization by using field emission scanning electron microscopy (FESEM) showed the $\mathrm{TiO}_{2}$ NPs possess a uniform semi-spherical shape in the size range of $33-48 \mathrm{~nm}$. The energy dispersive $X$-ray (EDX) spectra of green $\mathrm{TiO}_{2}$ NPs showed two peaks for the main elements of $\mathrm{Ti}$ (61 Wt.\%) and $\mathrm{O}$ (35 Wt.\%). The band-gap energy of $3.2 \mathrm{eV}$ was determined using UV-Vis spectroscopy. From the nitrogen sorption analysis, type $\mathrm{V}$ isotherm of the material was obtained, with BET surface area of $31.77 \mathrm{~m}^{2} / \mathrm{g}$. The photocatalytic activity of synthesized $\mathrm{TiO}_{2}$ was evaluated for photodegradation of methyl orange $(\mathrm{MO})$ under UV light irradiation. Based on the results, it is shown that $\mathrm{TiO}_{2} \mathrm{NPs}$ synthesized with $D$. pinnata leaves extracted using ethyl acetate showed the most effective photodegradation performance, achieving $98.7 \%$ of $\mathrm{MO}$ conversion within $150 \mathrm{~min}$. It can be concluded that the use of plant extracts in synthesis with $\mathrm{TiO}_{2}$ managed to produce highly crystalline anatase $\mathrm{TiO}_{2}$ with superior photocatalytic activity in the photodegradation of organic dye.

Keywords: $\mathrm{TiO}_{2}$, green synthesis, Deinbollia pinnata, solvents polarities, methyl orange, photodegradation 


\section{INTRODUCTION}

The nature of nanostructured materials has prompted natural product researchers' attention to this field. The naturally occurring oxide of titanium (IV) oxide or titania $\left(\mathrm{TiO}_{2}\right)$ possesses unique optical and electronic properties (Ahmad et al., 2019). The surface chemistry of nanostructures in terms of smaller size and uniqueness have already been utilized in medicine, nutrition, energy (Venugopal et al., 2017; Agarwal et al., 2018; Kim et al., 2018) and in the biosynthesis of $\mathrm{TiO}_{2}$ NPs with metabolites present in plants extract to reduce and stabilize bulk metal into elemental forms (Mohamad et al., 2014). Plants are a major segment of biodiversity affected by many living and non-living components with their medicinal values. This is due to the presence of certain chemicals/active ingredients used for the treatment of disorders, with low cost, eco-friendliness and easy availability in the forest (Patel, 2015). Stable biological NPs are achieved with appropriate choice of solvents polarity for plant extraction (reducing agents) and as toxic-free material (Raghad et al., 2016). Fungi, actinomycetes, bacteria, and plant extracts (Órdenes-Aenishanslins et al., 2014) have replaced chemical agents in the green synthesis materials. Furthermore, the usage of these materials can enhance the photocatalytic and pharmacological properties of the NPs produced. Biomediated $\mathrm{TiO}_{2}$ NPs have also been obtained from the extracts of Morinda citrifolia L. (Sundrarajan et al., 2017), Tamarindus indica (Hiremath et al., 2018); and Azadirachta indica (Thakur et al., 2019). The roots and leaves of $D$. pinnata are used in folkloric medicine as remedy for febrifuge, analgesic, bronchiasis intercostals, intestinal pains, jaundice, cough, asthma, and infections (Sotubo et al., 2016). Leaf extracts are used in fetus positioning during child birth (Kankara et al., 2015). The root act as an antibacterial agent (Sotubo et al., 2016).

Various synthesis methods of $\mathrm{TiO}_{2} \mathrm{NPs}$ are available, such as solution combustion (Kitamura et al., 2007), sol-gel (Elbushra et al., 2018), hydrothermal (Bregadiolli et al., 2017), solvothermal (Dinh et al., 2012), microwave-assisted (May-Masnou et al., 2018), co-precipitation (Rab et al., 2018), and chemical vapor deposition (Lee et al., 2011). However, the sol-gel process clearly stood out due to the lower processing temperature $\left(<100^{\circ} \mathrm{C}\right)$, which can produce highly crystalline particles with small sizes and high surface area. In addition, this method is also low in cost and can give fast composition homogeneity.

Dyes are major coloring agents used in industries for precious stones, paper, leather, plastic, textile, and food production. Hazardous waste water from dyeing process act as a major contaminant to the environment (Murugan and Parimelazhagan, 2014; Hejazi et al., 2020). The dye effluents are usually non-biodegradable, highly oxidizing, and stable to heat and light (Khataee and Mirzajani, 2010; Khataee et al., 2010) which attributed to their toxicity, undesirable aesthetic, and carcinogenicity (Khalik et al., 2017). This is due to their diversity and complex structure (Benkhaya et al., 2017), which need to be degraded. One example is methyl orange (MO), which is a commonly used dye.

Methyl orange dyes are stable under visible light, which can be easily degraded in the presence of catalyst (Chiu et al., 2019). It is known to cause irritation to reproductive, excretory, respiratory. and central nervous systems when in contact or consumed (Parida et al., 2013; Ljubas et al., 2015). Among all other methods to overcome its environmental hazard, photocatalysis has been proven effective for its degradation and removal of azo dyes in a less harmful (greener) method (Guettaï and Ait Amar, 2005). This present work focuses on the sol-gel green synthesis of $\mathrm{TiO}_{2} \mathrm{NPs}$ using $D$. pinnata plant extracts obtained by different solvents with different polarities ( $n$-hexane, ethyl acetate, and methanol). Their multi-functional group in the ethyl acetate crude extracts were characterized by Fourier transform infrared (FTIR) spectroscopy. The $\mathrm{TiO}_{2} \mathrm{NPs}$ obtained were then characterized using X-ray diffraction (XRD), field emission scanning electron microscopy (FESEM), the energy dispersive $\mathrm{X}$-ray (EDX), ultraviolet-visible light analysis (UV-Visible), nitrogen sorption analysis ( $\mathrm{N}_{2}$ sorption), and photoluminescence analysis (PL). Following that, the photocatalytic activity of the synthesized $\mathrm{TiO}_{2}$ NPs was evaluated for the photocatalytic degradation of $\mathrm{MO}$ under UV light irradiation. This current work further shows the potential of utilizing plants extract in multi-fold directions, but such as in the case of biosynthesis.

\section{EXPERIMENTAL}

\section{Materials}

The materials used in this research were titanium isopropoxide (TTIP), $\mathrm{C}_{12} \mathrm{H}_{28} \mathrm{O}_{4} \mathrm{Ti}$ [Aldrich (97\%)], methyl orange (MO) $\mathrm{C}_{14} \mathrm{H}_{14} \mathrm{~N}_{3} \mathrm{NaO}_{3} \mathrm{~S}$ [Aldrich (85\%)], absolute ethanol (EtOH) $\mathrm{C}_{2} \mathrm{H}_{6} \mathrm{O}$ [MERK (100\%)]. All materials were used as-received without further purification. Deionized water $\left(\mathrm{MQ}-\mathrm{H}_{2} \mathrm{O}\right)$ was used throughout the experiments. Mettler H10, photoreactor chamber, membrane filter, syringe, centrifuge, UV lamp 1,200 W, glass beaker, cuvette, aluminum foil, and glass petri-dish were used as the apparatus in this work.

The D. pinnata (Poir.) Schumach. and Thonn leaves were collected from Okehi Local Government Area of Kogi State, Nigeria during dry season, early January, for 1 week (daytime temperature ranges from $28^{\circ} \mathrm{C}$ in January to $32^{\circ} \mathrm{C}$ ). The plant was identified and confirmed at the Biological Department, Federal College of Education Okene Kogi State by Mrs. Aniama S.O.A., a botanist. The plant material was authenticated at Forestry Research Institute of Nigeria Ibadan through comparison with voucher specimen under accession number of FHI 3251. The leaves were collected, washed and air dried at room temperature for 1 month.

\section{Extraction}

Powdered plant material of $D$. pinnata (Poir.) Schumach. and Thonn was extracted using sonication method as shown in Figure 1. Briefly, the leaf samples were placed into several conical flasks (30 g each) and extracted with organic solvents $(150 \mathrm{~mL})$, which were $n$-hexane, ethyl acetate, and methanol, in a sonicator using ultrasonic-assisted extraction method for $10 \mathrm{~min}$ with agitation. This method utilizes the following software conditions of time, temperature, and solvent ratio. Upon completion, the samples were filtered into bottles and allowed to settle for $24 \mathrm{~h}$. 


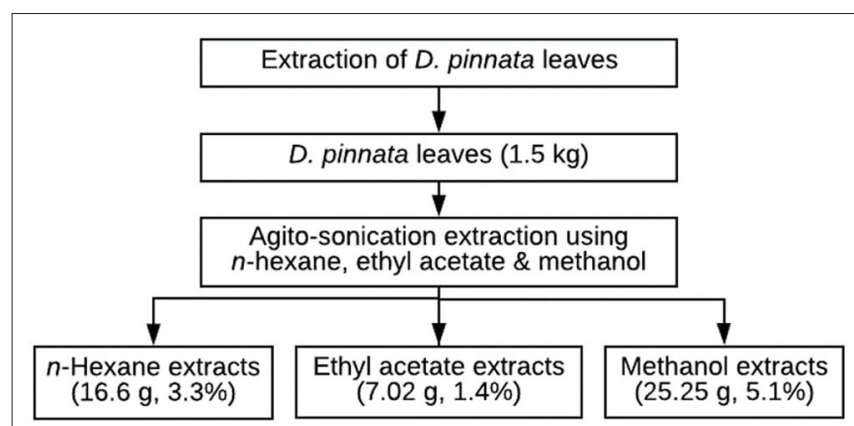

FIGURE 1 | Extraction steps of $D$. pinnata leaves.

The combined filtrates were then concentrated in vacuo at $40^{\circ} \mathrm{C}$ using a rotary evaporator.

\section{Qualitative Phytochemical Screening of Extract}

The $D$. pinnata ethyl acetate extract was subjected to chemical tests for the identification of their active constituents. The chemical tests were performed using the methods reported by Samkeliso et al. (2018).

\section{Test for Phenols}

Five percent ferric chloride was added to $2 \mathrm{~mL}$ of the leaf extract, which will show black coloration. This indicates the presence of phenols.

\section{Test for Flavonoids}

Ten milliliters of ethyl acetate was added to the leaf extract and the test tube containing this mixture was heated in the water bath. One milliliter of diluted ammonia was added to this mixture, which will give yellow color, showing the presence of flavonoids.

\section{Test for Alkaloids (Mayer's Test)}

Mayer's test reagent was added to $2 \mathrm{~mL}$ of the leaf extract, which will then give cream colored precipitation, indicating the presence of alkaloids.

\section{Test for Steroids}

Two milliliters of concentrated $\mathrm{H}_{2} \mathrm{SO}_{4}$ was added to $1 \mathrm{~mL}$ of the extract. Following that, $2 \mathrm{~mL}$ of acetic anhydride was added. The change in the color of extract from violet to blue or green will take place if steroids are present.

\section{Test for Coumarins}

Ten percent of the $\mathrm{NaOH}$ was added to the extract and chloroform was added. Formation of yellow color will show the presence of coumarin.

\section{Synthesis of Green $\mathrm{TiO}_{2}$ NPs}

The synthesis was carried out using the sol-gel method, where titanium (IV) isopropoxide (TTIP) was utilized as the precursor, D. pinnata extracts $[1 \mathrm{~g} / 5 \mathrm{~mL}]$ and deionized (DI) water as the medium. $\mathrm{TiO}_{2} \mathrm{NP}_{\mathrm{S}}$ were prepared by dissolving $4 \mathrm{~mL}$ TTIP with $20 \mathrm{~mL}$ of DI water under constant stirring for $30 \mathrm{~min}$ at $30^{\circ} \mathrm{C}$. This was followed by the gradual addition of $0.2 \mathrm{~g} / \mathrm{mL}$ of $D P$ extracts (either by $n$-hexane, ethyl acetate, or ethanol) with constant stirring at $50^{\circ} \mathrm{C}$ for $4 \mathrm{~h}$ before kept at room condition for $48 \mathrm{~h}$ of aging process. The resulting colloidal suspension was washed with ethanol and centrifuged three times at 10,000 $\mathrm{rpm}$ for $30 \mathrm{~min}$. The samples were then dried at $95^{\circ} \mathrm{C}$ for $24 \mathrm{~h}$ in an oven, before being calcined at $500^{\circ} \mathrm{C}$ in a muffle furnace for $5 \mathrm{~h}$. The calcined $\mathrm{TiO}_{2}$ NPs powder was further characterized spectroscopically.

\section{Characterizations of Green $\mathrm{TiO}_{2}$ NPs}

The crystallinity of the synthesized $\mathrm{TiO}_{2}$ NPs were performed by Rigaku Smart Lab, Germany with $\mathrm{Cu} \mathrm{K \alpha}$ radiation $(\lambda=$ $1.5418 \AA$ ) operated at $40 \mathrm{kV}$ and $30 \mathrm{~mA}$. The diffraction pattern was scanned in the $2 \theta$ range of $20-90^{\circ}$. The morphological features and surface characteristics of the photocatalyst were characterized using field emission scanning electron microscopy (FESEM) (JEOL JSM 6710F) equipped with EDX, at an accelerating voltage of $0.5-30 \mathrm{kV}$ to determine the surface chemical element contents of the photocatalysts. The band gap energy of the $\mathrm{TiO}_{2}$ NPs were determined using UV-Vis near-IR (UV-Vis-NIR) spectrophometer (Shimadzu UV-3600 Plus UVVIS-NIR). The spectra were recorded in the range of 300-500 nm at temperature rate/hold/time of 10:1,000:1. The specific surface area, micropore and pore size distribution of the $\mathrm{TiO}_{2} \mathrm{NPs}$ were obtained using a multipoint Brunauer-Emmett-Teller (BET) analysis through the measurement of nitrogen adsorptiondesorption isotherm as a function of relative pressure from a Quantachrome NOVA-4LX firmware with helium gas, and ambient temperature of $30.06^{\circ} \mathrm{C}$. The thermal stability and heat flow were examined using thermogravimetric-differential scanning calorimetry analyzer (TGA-DSC, SHIMADZU DTG-60H). The scanning was performed within the furnace temperature range of $20-800^{\circ} \mathrm{C}$ with a heating rate and air

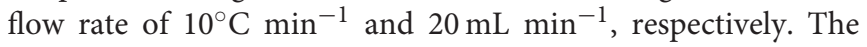
electrons-holes recombination's of the photocatalysts through discrete electronic states were analyzed by Photoluminescence (Horiba-fluoroMax-4C spectrofluorometer) with emission of full spectrum range between 400 and $800 \mathrm{~nm}$. The chemical functional groups were detected by Fourier transform infrared spectroscopy (1600 FT-IR). The spectra were recorded in the range of $400-4,000 \mathrm{~cm}^{-1}$ using PerkinElmer Spectrum One Spectrometer.

\section{Photocatalytic Testing}

The photocatalytic activity of the green $\mathrm{TiO}_{2} \mathrm{NPs}$ was tested out in the degradation of methyl orange (MO, Aldrich 85\%) using a 1,200 W lamp UV light source spaced at $3 \mathrm{~cm}$ horizontally. Prior to the test the stock solution of the water-based MO was prepared at $1,000 \mathrm{ppm}$ in $100 \mathrm{~mL}$ and allowed to stand for $24 \mathrm{~h}$. This was then followed by serial dilutions of $5,10,15,20$, 25 , and $30 \mathrm{ppm}$. Five dilutions were used for the calibration curve, as shown in Figure 2, where $R^{2}=0.9999$ was obtained from the straight line. For the reaction using the synthesized photocatalyst, the green $\mathrm{TiO}_{2} \mathrm{NPs}$ synthesized was added to MO solution $(50 \mathrm{~mL})$ and sonicated. The solution was stirred using a magnetic stirrer in the dark condition for $1 \mathrm{~h}$ in order to 


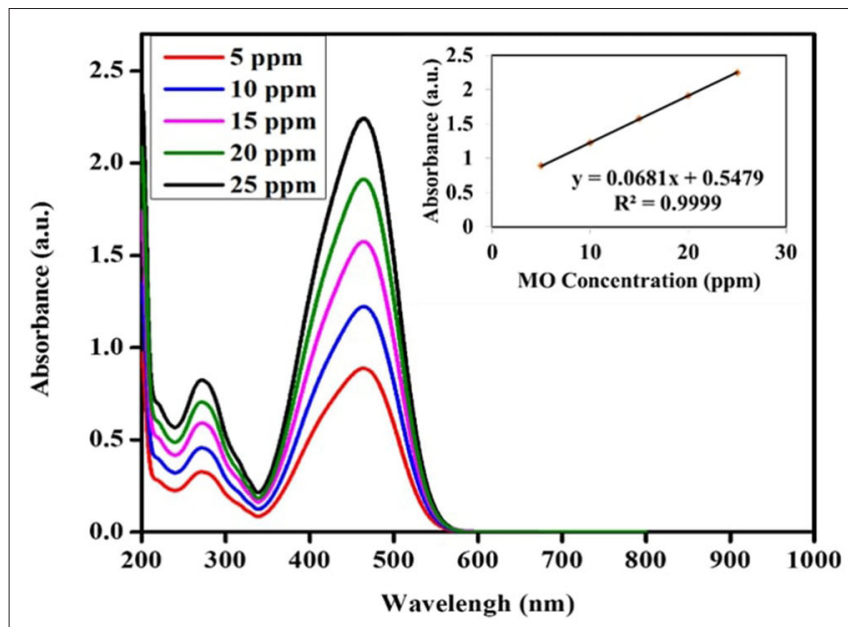

FIGURE 2 | Calibration curve spectra and line graph of M.O. Solution.

reach the adsorption equilibrium. After reaching the adsorption equilibrium, the UV light was switched on $3 \mathrm{~mL}$ of the treated MO was collected after interval of $30,60,90,120$, and $150 \mathrm{~min}$ of reaction. The concentration of the MO from the withdrawn aliquot was analyzed using a UV-Vis spectrophotometer.

\section{RESULTS AND DISCUSSION}

\section{Possible Mechanism for the Formation of $\mathrm{TiO}_{2}$ NPs}

Preliminary phytochemical screening was done using standard procedures to identify the constituents present in the extract, as described by Samkeliso et al. (2018). It involves observing plant samples for different classes of phytochemicals. This qualitative tests were used to provide an indication of the nature of phytochemicals present in D. pinnata (Poir.) Schumach. and Thonn's extract, as shown in Table 1.

Table 1 shows that the plant of $D$. pinnata contains high amount of flavonoids and phenols that are important as surfactants and stabilizers. These constituents are able to prevent excessive agglomeration of the nanoparticulate material during the synthesis process. Other phyto-constituents present in the leaf extract were alkaloids, stereoids, and coumarins.

The mechanism for the formation of $\mathrm{TiO}_{2}$ is shown in Figure 3. $\mathrm{TiO}_{2}$ synthesis begins with complete hydrolysis of the precursor used [titanium isopropoxide, $\mathrm{Ti}(i-\mathrm{OPr})_{4}$ ] by direct interaction of the titanium source with water. Titanyl hydroxide was obtained according to the following reaction (Solano et al., 2019):

$$
\mathrm{Ti}\left(\mathrm{i}-\mathrm{OC}_{3} \mathrm{H}_{7}\right)_{4}+3 \mathrm{H}_{2} \mathrm{O} \rightarrow \mathrm{TiO}(\mathrm{OH})_{2}+4 \mathrm{C}_{3} \mathrm{H}_{7} \mathrm{OH}
$$

The FTIR data of $D$. pinnata ethyl acetate leaf extract displays the presence of a broad peak for $\mathrm{OH}$ functional group in the spectrum (Figure 13). It shows that the extract contains compounds having hydroxyl group as a functional group in the structure. Titanyl hydroxide can be dehydrated to give $\mathrm{TiO}_{2}$
TABLE 1 | Phytochemical constituents present in ethyl acetate leaf extracts of $D$. pinnata.

\begin{tabular}{lc}
\hline Constituents & Results \\
\hline Phenolics & +++ \\
Flavonoids & +++ \\
Alkaloids & ++ \\
Steroids & ++ \\
Coumarins & ++ \\
\hline
\end{tabular}

nanoparticles by heating it with ethyl acetate leaf extracts of D. pinnata at about $50^{\circ} \mathrm{C}$. In this process, D. pinnata extract serves as catalysts due to the present of compounds having hydroxyl group as a functional group in the structures (Selvaraj et al., 2012). Hence the reaction between $D$. pinnata extract and $\mathrm{TiO}(\mathrm{OH})_{2}$ might occur through the possible pathway which is described in Figure 3. Hence, water soluble compounds containing hydroxyl functional group are reported to be responsible for the stabilization of $\mathrm{TiO}_{2}$ nanoparticles.

\section{Physicochemical Properties Green $\mathrm{TiO}_{2}$ NPs}

In this research, green $\mathrm{TiO}_{2}$ NPs were successfully prepared by the sol-gel method using $D$. pinnata plant, extracted by different solvents with different polarities ( $n$-hexane, ethyl acetate, and methanol). First, the preparation of green $\mathrm{TiO}_{2}$ NPs colloid was obtained by gradual addition of extracts into the continuously stirred titanium isopropoxide in distilled water. Subsequently, $\mathrm{TiO}_{2}$ NPs were washed with absolute ethanol several times and calcined at $500^{\circ} \mathrm{C}$, before being characterized.

For the crystallinity studies done using XRD, as shown in Figure 4, the major peaks were at $2 \theta$ values of $25.18^{\circ}$ (101), $37.73^{\circ}(004), 47.94^{\circ}(200), 53.76^{\circ}(105)$, and $54.96^{\circ}$ (211), which indicated the successful synthesis of anatase $\mathrm{TiO}_{2} \mathrm{NP}_{\mathrm{S}}$. The XRD pattern confirmed the synthesized $\mathrm{TiO}_{2}$ consist of anatase phase in high purity, with average crystallite size in the range of 19$21 \mathrm{~nm}$. Scherer's equation (Lima et al., 2018), which relates the size of sub-micrometer crystallites in a solid to broadening of a sample peak in a diffraction pattern' illustrated as; $D=K \lambda / \beta \cos \theta$ where $(D)$ is average crystal size for the main broadening anatase peak; $K=$ Scherrer's coefficient constant (0.89) which depend on the crystallite shape, $\lambda=\mathrm{X}$-ray wavelength; $\beta=$ full width at half maximum intensity (FWHM) of diffraction peaks in radians and $\theta=$ Bragg's angle, has been used to correlate the sample analysis reference pattern. The average crystallite size of the synthesized $\mathrm{TiO}_{2}$ was $11 \mathrm{~nm}$, which showed similarity with $\mathrm{TiO}_{2}$ NPs synthesis using the extracts of Syzygium cumini, as reported by Sethy et al. (2020). The order of their lattice parameters is as follows: the fraction from ethyl acetate $(\mathrm{a}=3.79632, \mathrm{~b}=$ 9.52847 $)>n$-hexane $(\mathrm{a}=3.79223, \mathrm{~b}=9.51600)>$ methanol $(\mathrm{a}=3.79237, \mathrm{~b}=9.51330)$, which indicates the qualitative merit for the fraction obtained by ethyl acetate $[(0.149)>n$ hexane fraction $(0.136)>$ methanol extracts $(0.121)$ ]. This is indirectly proportional to their $2 \theta$ vales of (101), where ethyl acetate fractions with $25.2324<n$-hexane fractions at 25.2607 


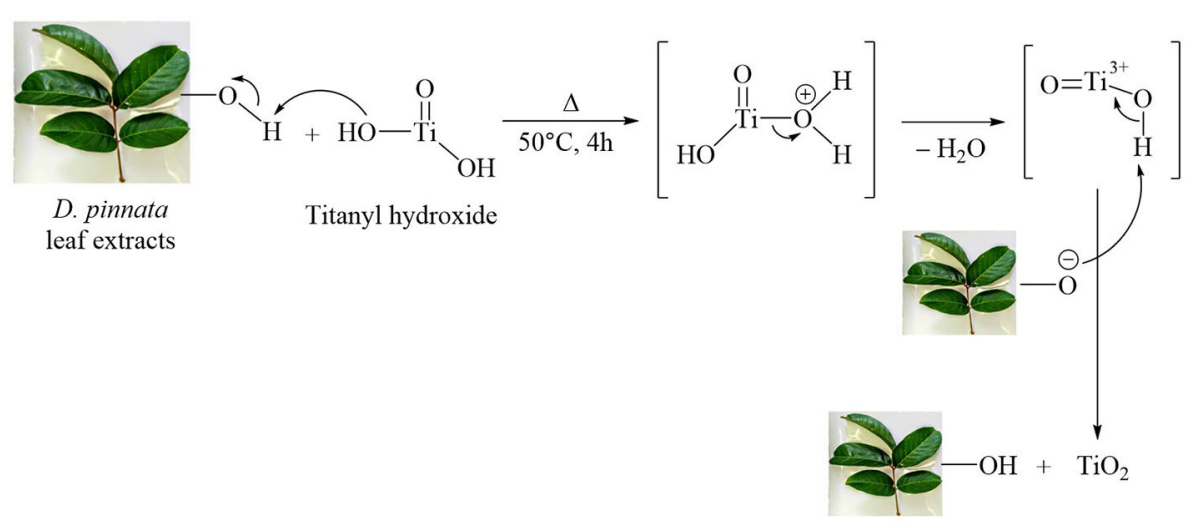

FIGURE 3 | Possible reaction mechanism for the formation of $\mathrm{TiO}_{2} \mathrm{NPs}$ in presence of hydroxyl group $(-\mathrm{OH})$ of leaf extract of $D$. pinnata.

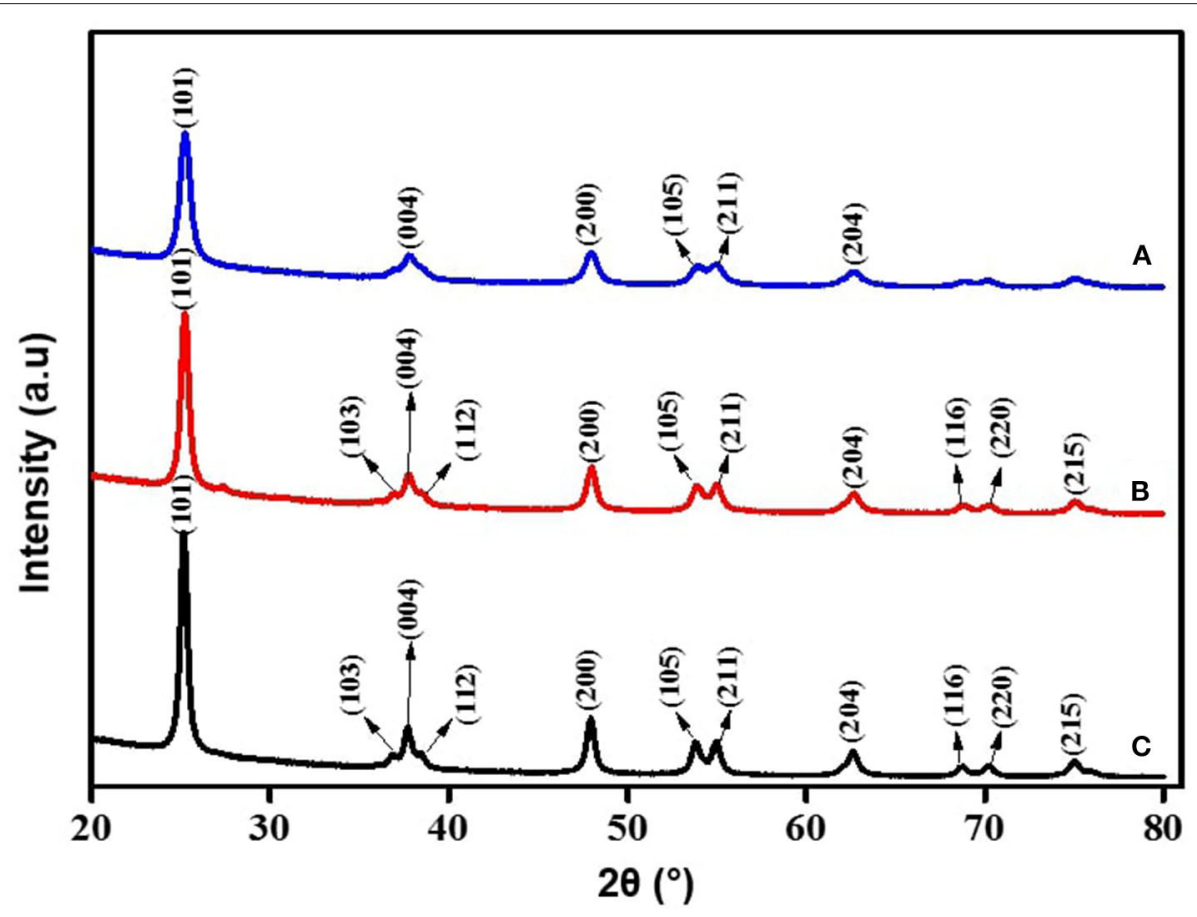

FIGURE 4 | XRD patterns of green $\mathrm{TiO}_{2}$ NPs synthesized from the extracts of $D$. pinnata plant using (A) methanol, (B) $n$-hexane, and (C) ethyl acetate as the extraction solvents.

$<$ methanol fractions at the value of 25.2608. Thus, XRD morphological studies showed significant crystallinity, crystal phase, and peak sharpness of green $\mathrm{TiO}_{2}$ obtained using ethyl acetate plant extracts compared to those of methanol and $n$-hexane fractions, by comparing their major peaks, lattice parameter, and qualitative merit. Since $\mathrm{TiO}_{2}$ synthesized with the extracts of $D$. pinnata plant using ethyl acetate as solvent showed better results, further characterizations were focused on the ethyl acetate green $\mathrm{TiO}_{2} \mathrm{NP}_{S}$. The crystallographic database (DB card number 5000223) did match with the tetragonal anatase of high purity indexed at 97.55 (15\%), as displayed in Figure 5. The 3Dtetragonal crystal structure showed a supportive lattice parameter at $\mathrm{a}=3.7963 \AA$ and $\mathrm{c}=9.52847 \AA$ with angle of $90^{\circ}$. The quantitative analysis showed a figure of merit at 0.149 with a space group at 141: 141/amd:1. Such crystallinity, crystal phase, and peak sharpness of green $\mathrm{TiO}_{2} \mathrm{NP}_{\mathrm{S}}$ anatase were reported to influence their application as catalyst (Kim et al., 2018) or as support (Bagheri et al., 2014), acting as gas sensor (Zakrzewska and Radecka, 2017), degradation of pollutants (Phuinthiang and Kajitvichyanukul, 2019) and in solar cell (Kang et al., 2019).

The FESEM images of green $\mathrm{TiO}_{2} \mathrm{NP}_{\mathrm{S}}$ synthesized from the extracts of $D$. pinnata plant, obtained by ethyl acetate, with different magnifications, are shown in Figure 6. The size of the particles were in the range of $19-21 \mathrm{~nm}$, and the particles were 


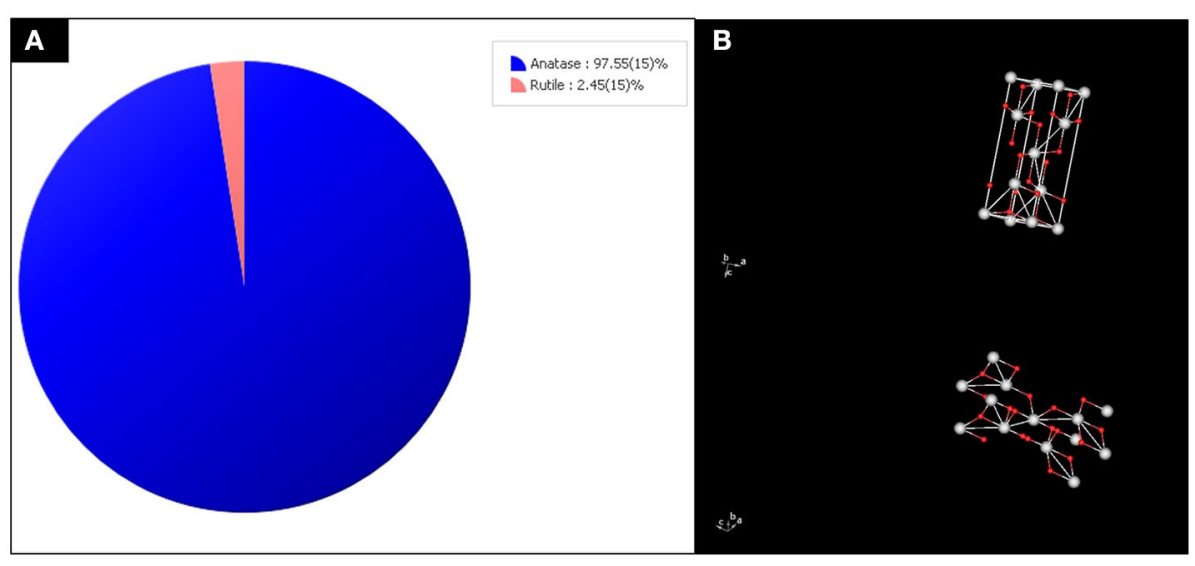

FIGURE 5 | (A) The purity index and (B) 3D-tetragonal structure of anatase $\mathrm{TiO}_{2}$ obtained from the XRD results.

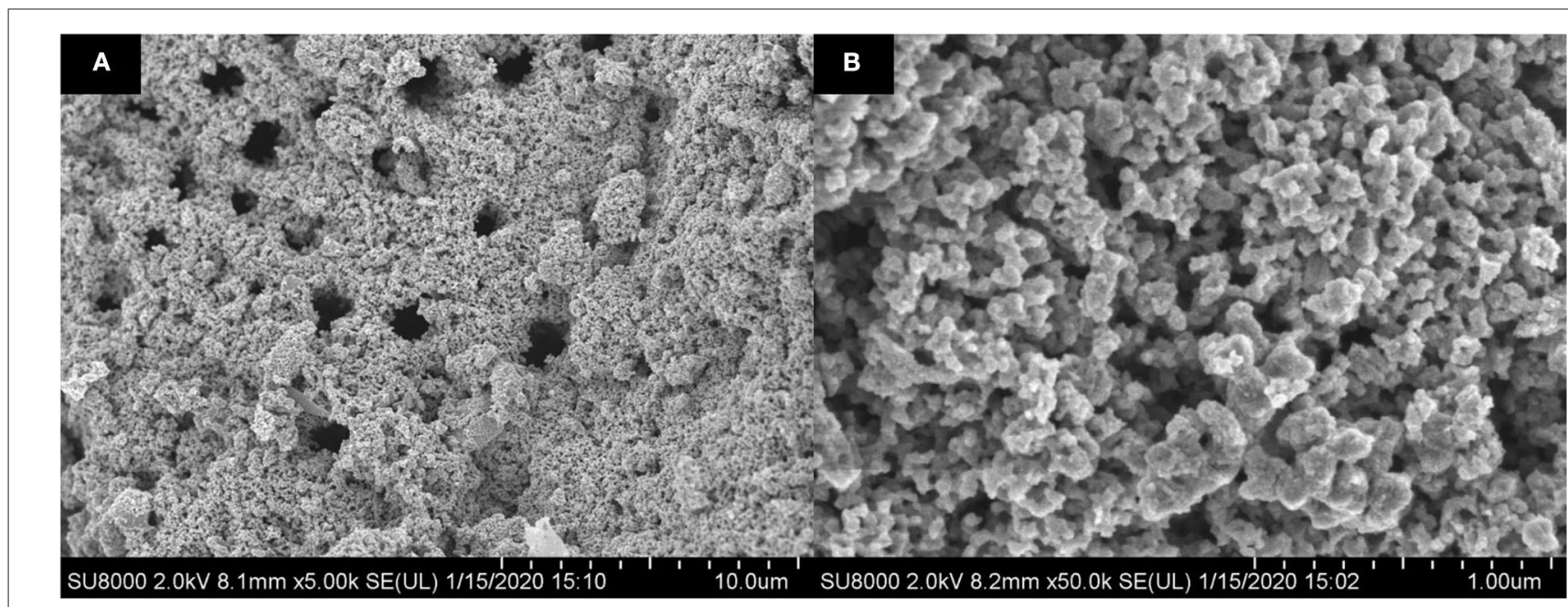

FIGURE 6 | FESEM images of synthesized green $\mathrm{TiO}_{2}$ NPs with magnifications of (A) 5,000 times and (B) 50,000 times.

densely aggregated, with non-uniformed semi-spherical shapes. This also proved that $\mathrm{TiO}_{2}$ particles in nano-sized have been successfully obtained.

The elemental analysis was performed via EDX. The EDX line scan spectrum of calcined $\mathrm{TiO}_{2}$ NPs in Figure 7 shows two peaks as the main chemical composition, which were Ti (61 wt.\%) and $\mathrm{O}$ (35 wt.\%). This is also consistent with the results obtained in the XRD analysis. The nonstoichiometric of $\mathrm{TiO}_{2}$ with the presence of oxygen can contribute to high performance in photocatalytic activity (Liu et al., 2012) with intense peak as bulk $\mathrm{TiO}_{2}$ and less intense peak as surface $\mathrm{TiO}_{2}$ (Ebrahimian et al., 2017). The EDX spectrum analysis showed that no other impurities were present in the synthesized green $\mathrm{TiO}_{2}$ NPs, which proved its high purity level.

The optical absorption properties of the green $\mathrm{TiO}_{2} \mathrm{NPs}$ were studied by UV-Vis-NIR as the absorption potential is an important factor to reflect its photocatalysis. The wavelength dependent absorbance was within the range of $300-500 \mathrm{~nm}$. The band gap energy $\left(E_{g}\right)$ was calculated using this equation; $E_{g}=$ $1239.8 / \lambda$ in (Parida et al., 2013; Ljubas et al., 2015) where the absorption spectrum has a wavelength value of $378 \mathrm{~nm}$, which indicated typical $\mathrm{TiO}_{2}$ anatase with high crystallinity as also reported by (Li et al., 2019), and band gap energy of $3.2 \mathrm{eV}$, as shown in Figure 8.

The $\mathrm{N}_{2}$ isotherm and pore size distribution (inset) of the synthesized $\mathrm{TiO}_{2}$ NPs are shown in Figure 9. The isotherm is of type $\mathrm{V}$ isotherm, where a hysteresis loop can be seen. This indicates that the distribution of pores in an irregular flow rate (Tan et al., 2012). The BJH pore size distribution based on desorption branch showed major peaks starting from 2.02 to $6.00 \mathrm{~nm}$ with a broad peak at $3.98 \mathrm{~nm}$, showing the mesoporosity. As for the specific surface area of synthesized $\mathrm{TiO}_{2} \mathrm{NPs}$, it was examined through BET multipoint graph, as shown in Figure 10. The BET surface area of the green $\mathrm{TiO}_{2} \mathrm{NPs}$ was found to be $31.77 \mathrm{~m}^{2} / \mathrm{g}$, which corresponds to correlation coefficient $(r)$ of 0.99 , as a liner graph (Ahmad et al., 2017). 


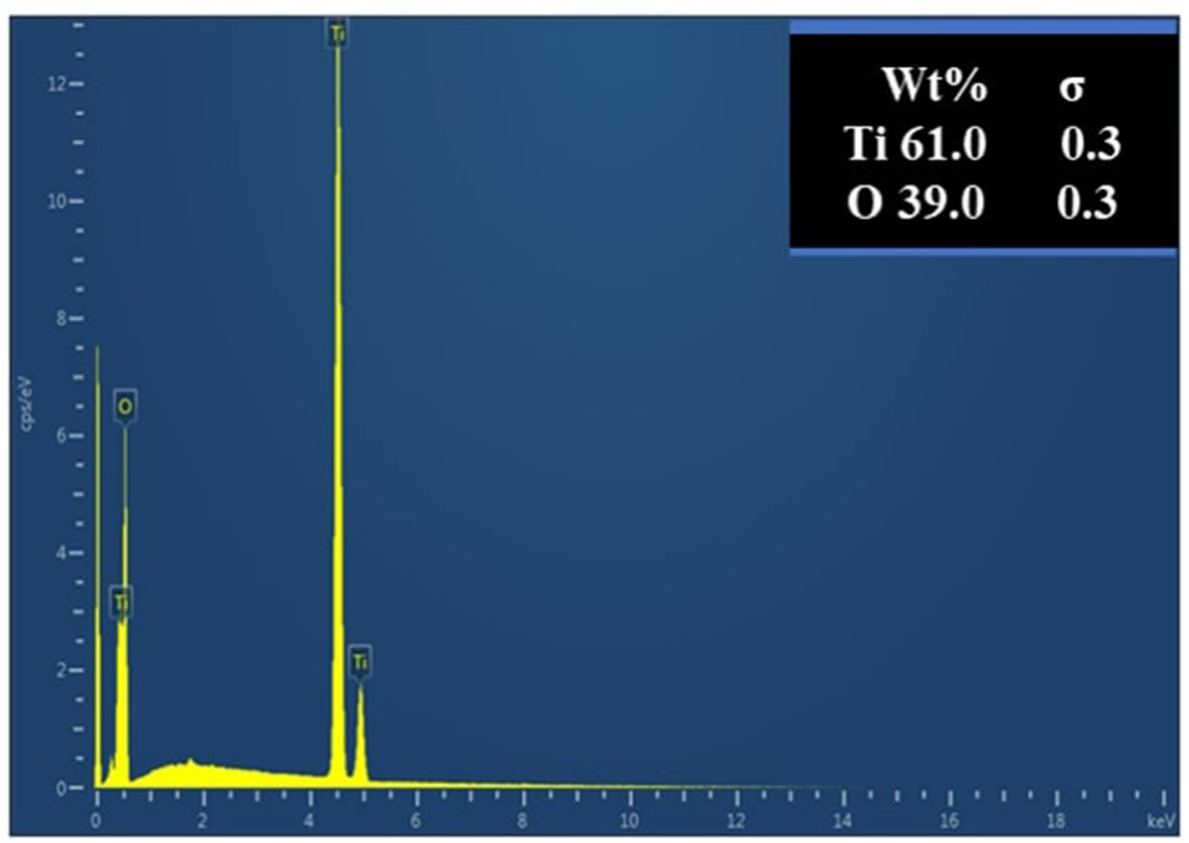

FIGURE 7 | EDX spectrum of green $\mathrm{TiO}_{2}$ NPs synthesized from the extracts of $D$. pinnata plant using ethyl acetate as the extraction solvent.

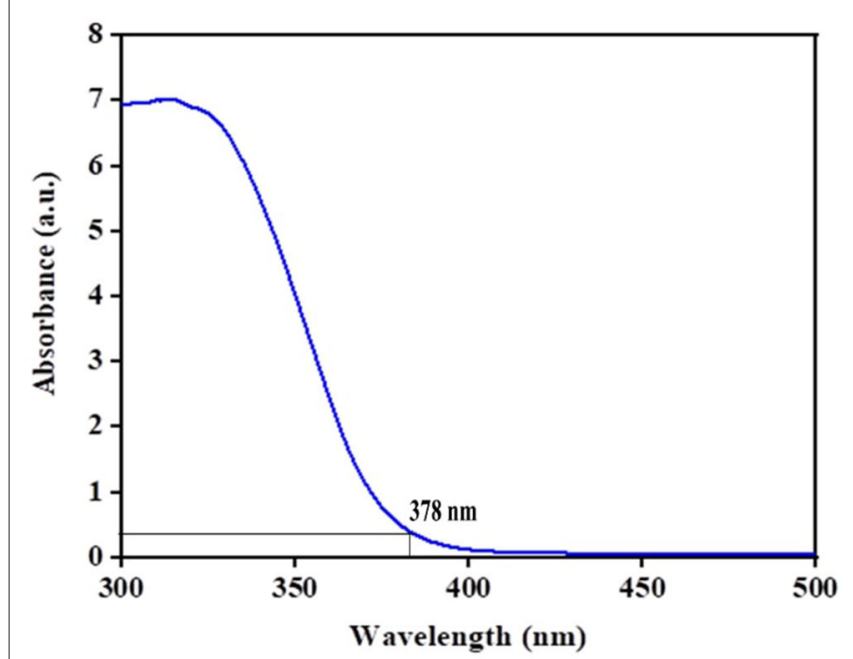

FIGURE 8 | UV-Vis of green $\mathrm{TiO}_{2} \mathrm{NPS}$.

Thermogravimetric analysis is a method used to determine thermal stability and the fractions of volatile components by monitoring the weight changes at a constant heating rate (Pintana and Tippayawong, 2013). The differential scanning calorimetry deals with the heat flow-temperature and this analysis has been carried out in the temperature range of 20$800^{\circ} \mathrm{C}$ using the uncalcined sample, as shown in Figure 11. The first weight loss band can be seen at $102^{\circ} \mathrm{C}$, which is attributed to the loss of adsorbed atmospheric water (Yang et al., 2017). The second noticeable peak at $278^{\circ} \mathrm{C}$ was assigned to lower

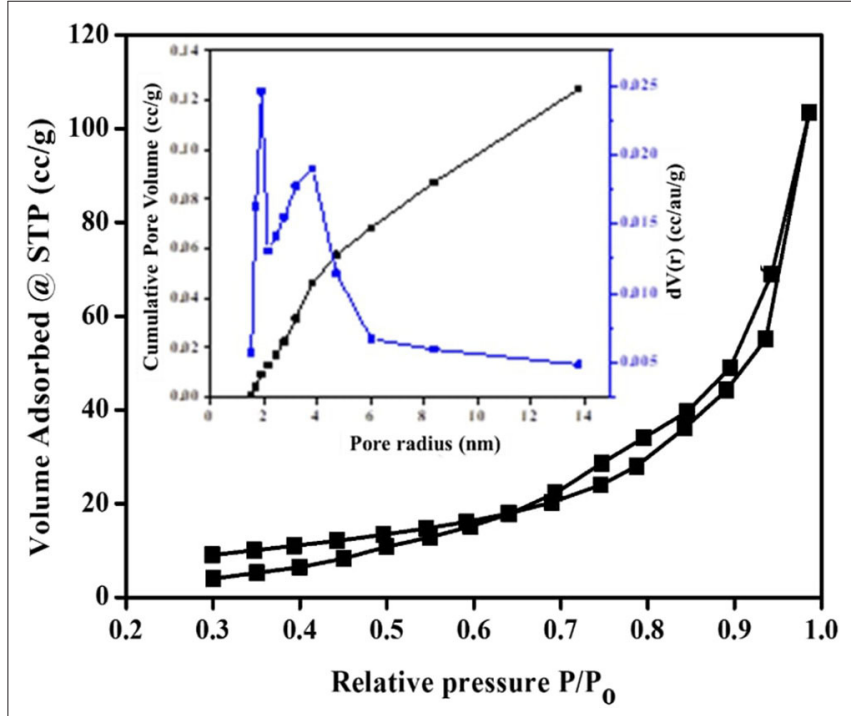

FIGURE 9 | $\mathrm{N}_{2}$ isotherm and pore size distribution (inset) of the synthesized $\mathrm{TiO}_{2} \mathrm{NPs}$.

molecular weight metabolites, such as long chain fatty acids, galloyl ester or long chain esters. The last weight loss at $503^{\circ} \mathrm{C}$ marked the decomposition of all organic compounds (Kim et al., 2018). The irregular band line shown in the spectrum may be attributed to the nature of the products formed. The higher percentage mass loss (70\%) was found for lower molecular weight constituents. The temperature at 106 and $288^{\circ} \mathrm{C}$ are associated with the loss of ethanol-water mixtures residue and 


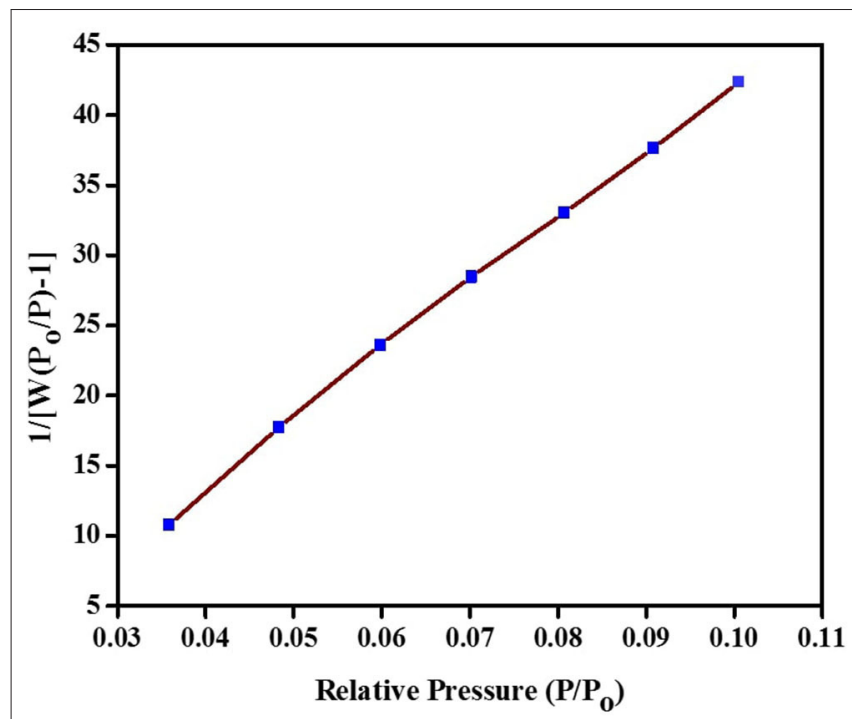

FIGURE 10 | BET plot of the synthesized green $\mathrm{TiO}_{2} \mathrm{NPs}$.

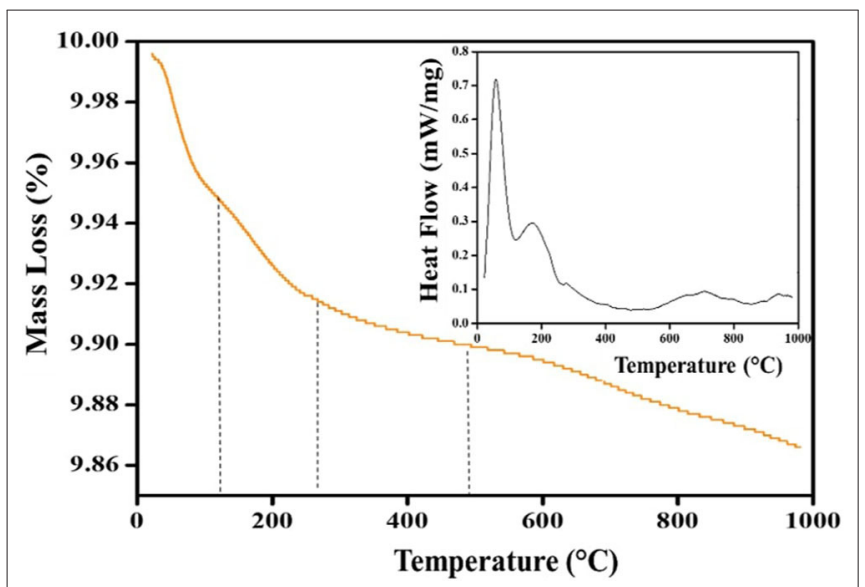

FIGURE 11 | The TGA and DSC (inset) curves of the synthesized green $\mathrm{TiO}_{2}$ NPS.

fatty acids/ester endothermically. The exothermic peaks at 98 and $180^{\circ} \mathrm{C}$ seen on the DSC curve may be attributed to early phase transformation (Marinescu and Sofronia, 2011). The third region at $500^{\circ} \mathrm{C}$ justified total phase transformation of residual organic constituents of high molecular weight strongly coordinated to $\mathrm{TiO}_{2}$ atoms such as triterpenoids.

Photoluminescence (PL) is also an important technique to study the optical properties of the synthesized $\mathrm{TiO}_{2} \mathrm{NPs}$. Figure 12 shows the $\mathrm{p}$ spectrum of the synthesized green $\mathrm{TiO}_{2}$ NPs. These NPs show a strong luminescent emission peak at $520.3 \mathrm{~nm}$ with irregular broad peak surfaces, in the green region, and a weak emission peak at $468.6 \mathrm{~nm}$ at room temperature. These transitions could be attributed to the complete interband formation in dxy orbital with phytoconstituents, implying

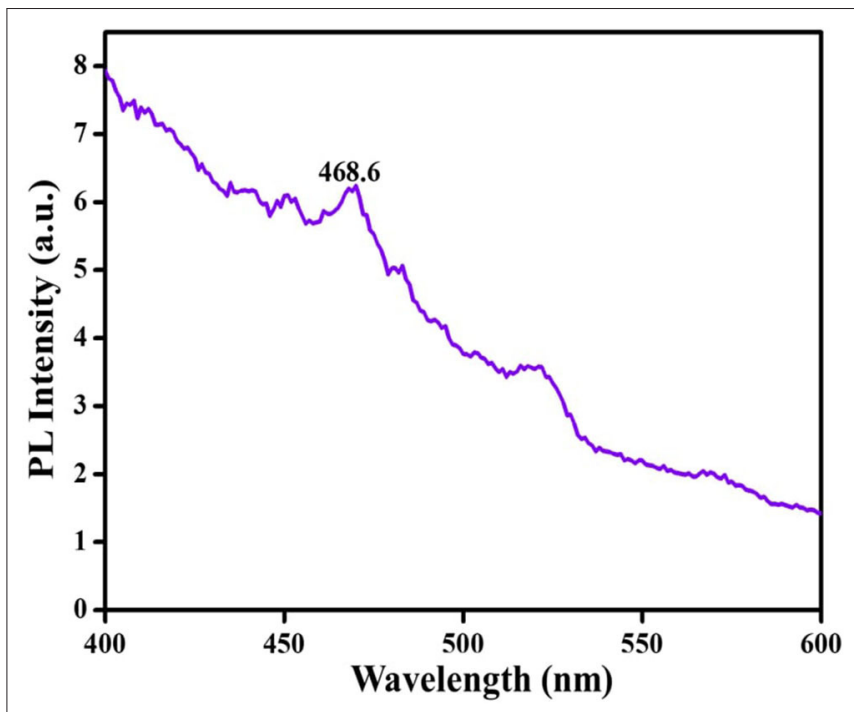

FIGURE 12 | PL spectrum of the synthesized green $\mathrm{TiO}_{2} \mathrm{NPs}$.

$3 \mathrm{~d}^{2} 4 \mathrm{~s}^{2}$, and $3 \mathrm{~d}^{0}$ in the $\mathrm{Ti}^{4+}$ ions (Yin et al., 2013). It was also observed that the second luminescence peak shifted toward the lower energy region. This may be attributed to the inter bonding of Ti-O from the carbonyl components in the plant signifying active anatase $\mathrm{TiO}_{2}$ of good light-response (Haghighatmamaghani et al., 2018). Furthermore, the shift toward the blue region may indicate a slight decrease in the particle sizes (Haque et al., 2017).

The FTIR spectrum of $D$. pinnata ethyl acetate extract and $\mathrm{TiO}_{2}$ NPs were indicated by Figures 13A,B, respectively. Absorption bands at 3,386, 2,927, 1,710, 1,612, 1,446, 1,043, and $756 \mathrm{~cm}^{-1}$ are due to $\mathrm{O}-\mathrm{H}$ bond stretching, $\mathrm{C}-\mathrm{H}$ bond stretching, $\mathrm{C}=\mathrm{O}$ bond stretching of carbonyl groups, $\mathrm{C}=\mathrm{C}$ bond stretching, $\mathrm{C}-\mathrm{O}$ bond bending vibration on phenolic compound, C-O bond stretching of the hydroxyl group, and out-of-plane $\mathrm{C}-\mathrm{H}$ bending for aromatic ring. These functional groups represent the phytochemicals present in the extract. In Figure 12B, the broad absorption band observed at $3,386 \mathrm{~cm}^{-1}$ represents $\mathrm{O}-\mathrm{H}$ bond stretching due to adsorbed moisture at the surface of $\mathrm{TiO}_{2}$ NPs. The broad band at $537 \mathrm{~cm}^{-1}$ represents a characteristic peak of Ti-O-Ti bending mode of vibration which confirms the formation of metal oxygen bonding (Catauro et al., 2018). The $\mathrm{TiO}_{2}$ NPs calcined at $500^{\circ} \mathrm{C}$ showed no traces of organic components functional groups, which justified complete calcination.

\section{Photocatalytic Activity}

The photocatalytic activity of the green $\mathrm{TiO}_{2}$ NPs synthesized using the extracts of $D$. pinnata leaves with ethyl acetate as the solvent was tested out in the photodegradation of MO under UV light irradiation $(1,200 \mathrm{~W})$. The light source played a vital role in photocatalytic degradation as semiconductor compounds, such as $\mathrm{TiO}_{2}$, degrades volatile and organic pollutants under UV light 

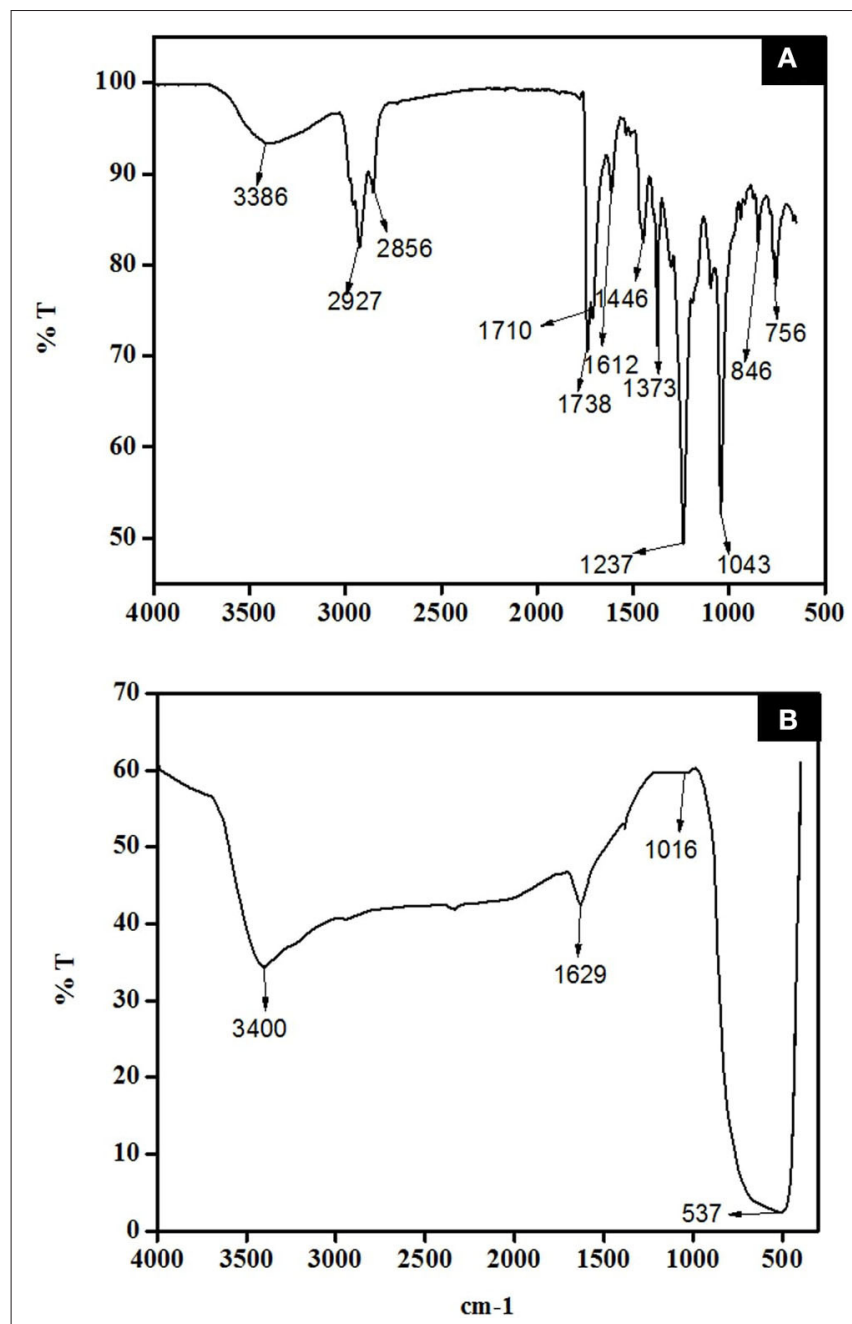

FIGURE 13 | FTIR spectra of (A) D. pinnata crude extract and (B) synthesized $\mathrm{TiO}_{2} \mathrm{NPS}$.

irradiation (Cun et al., 2002; Laoufi and Bentahar, 2014; Luan et al., 2014). MO dye was chosen as the model organic pollutant and the photodegradation process was monitored by UV-visible spectrophotometer in the range of $800-200 \mathrm{~nm}$. The degradation percentage was calculated using the following equation: $D(\%)$ $=\left(C_{i}-C_{f}\right) / C_{i} \times 100$ where $C_{i}$ is initial concentration, $C_{f}$ is final concentration of MO at time $(t)$ (Haque et al., 2017). Figure 14 shows the spectra of the reaction mixture withdrawn at intervals of $30,60,90,120$, and $150 \mathrm{~min}$. After only $90 \mathrm{~min}, 51.72 \%$ of MO has been degraded. It was also observed that at $120 \mathrm{~min}$, the photodegradation reached $81.36 \%$, while at $150 \mathrm{~min}, 97.53 \%$ of MO photodegradation was obtained. It is evident that the rate of photodegradation of green $\mathrm{TiO}_{2}$ NPs photocatalyst on $\mathrm{MO}$ increased with longer irradiation time. This indicate faster interaction between the photons and green $\mathrm{TiO}_{2}$ NPs, which showed direct proportionality to the duration of irradiation. Therefore, MO (20 ppm) showed optimum irradiation duration of $150 \mathrm{~min}(97.53 \%)$. This can signify rapid formation of $\bullet \mathrm{OH}$ radicals as active sites on the $\mathrm{TiO}_{2}$ NPs' surface for effective

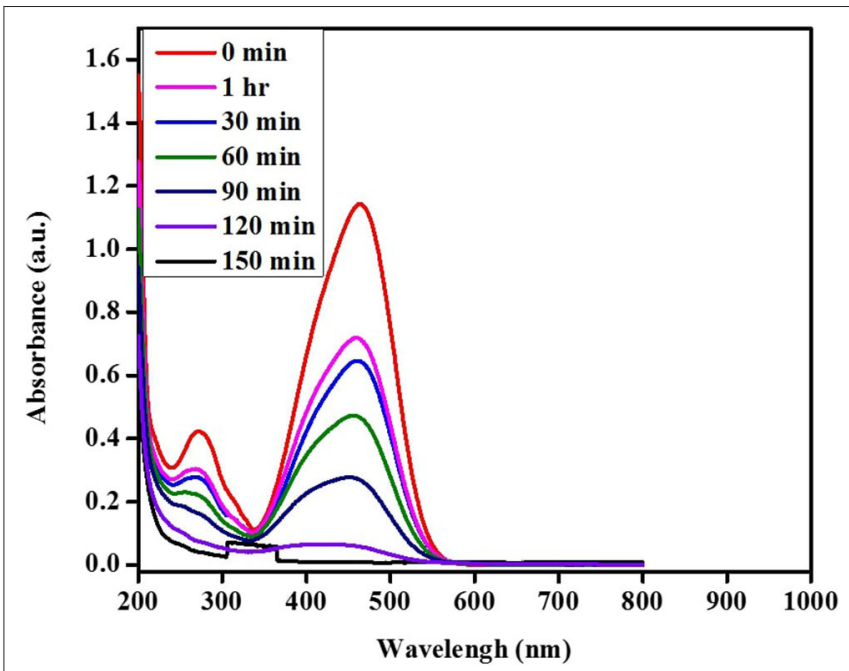

FIGURE 14 | Absorbance spectra of photocatalytic degradation pattern of $\mathrm{MO}$ solution.

adsorption throughout the reaction (Youssef et al., 2016). Based on these results, it can be seen that an optimal performance of green $\mathrm{TiO}_{2}$ NPs can be achieved within a short time. This may indicate that extracts from plants as green substitute for the synthesis of NPs has the benefits of enhancing the charge carrier's separation (Solano et al., 2019), increasing specific surface area and overall photocatalytic performance. The physicochemical properties and photocatalytic activity have justified the efficient performance of green synthesized $\mathrm{TiO}_{2}$ NPs from $D$. pinnata plant for the photodegradation of MO.

\section{CONCLUSION}

Based on the physicochemical characterization, $\mathrm{TiO}_{2} \mathrm{NPs}$ have been successfully synthesized using the extracts of $D$. pinnata leaves. Different solvents used in the extraction also showed the contributions of solvents polarity in the extractions, where in this work, extracts using ethyl acetate showed superior characteristics. The synthesized green $\mathrm{TiO}_{2}$ NPs also showed good photocatalytic activity in the photodegradation of methyl orange dye under UV light irradiation. The work here showed that $\mathrm{TiO}_{2} \mathrm{NPs}$ with good physicochemical properties and photocatalytic activity can be synthesized using extracts of plants, which can reduce or eliminate the use of harmful chemicals. Further work on the physicochemical properties and photocatalytic activity of $\mathrm{TiO}_{2}$ NPs obtained using extracts from $n$-hexane and methanol will be carried out.

\section{DATA AVAILABILITY STATEMENT}

The original contributions presented in the study are included in the article/supplementary materials, further inquiries can be directed to the corresponding author/s. 


\section{AUTHOR CONTRIBUTIONS}

All authors listed have made a substantial, direct and intellectual contribution to the work, and approved it for publication.

\section{FUNDING}

This research received funding from Ministry of Higher Education (MOHE) under the Fundamental Research

\section{REFERENCES}

Agarwal, H., Nakara, A., and Shanmugam, V. K. (2018). Anti-inflammatory mechanism of various metal and metal oxide nanoparticles synthesized using plant extracts: a review. Biomed. Pharmacother. 109, 2561-2572. doi: 10.1016/j.biopha.2018.11.116

Ahmad, S., Munir, S., Zeb, N., Ullah, A., Khan, B., Ali, J., et al. (2019). Green nanotechnology: a review on green synthesis of silver nanoparticles-an ecofriendly approach. Int. J. Nanomed. 14, 5087-5107. doi: 10.2147/IJN.S200254

Ahmad, T., Phul, R., Alam, P., Lone, I. H., Shahazad, M., Ahmed, J., et al. (2017). Dielectric, optical and enhanced photocatalytic properties of $\mathrm{CuCrO}_{2}$ nanoparticles. RSC Adv. 7, 27549-27557. doi: 10.1039/C6RA26888A

Bagheri, S., Muhd Julkapli, N., and Bee Abd Hamid, S. (2014). Titanium dioxide as a catalyst support in heterogeneous catalysis. Sci. World J. 2014, 1-21. doi: 10.1155/2014/727496

Benkhaya, S., El Harfi, S., and Elharfi, A. (2017). Classifications, properties and applications of textile dyes : a review. Appl. J. Environ. Eng. Sci. 3, 311-320. doi: 10.1016/j.heliyon.2020.e03271

Bregadiolli, B. A., Fernandes, S. L., and De Oliveira Graeff, C. F. (2017). Easy and fast preparation of $\mathrm{TiO}_{2}$-based nanostructures using microwave assisted hydrothermal synthesis. Mater. Res. 20, 912-919. doi: 10.1590/1980-5373-mr-2016-0684

Catauro, M., Tranquillo, E., Dal Poggetto, G., Pasquali, M., Dell'Era, A., and Ciprioti, S. V. (2018). Influence of the heat treatment on the particles size and on the crystalline phase of $\mathrm{TiO}_{2}$ synthesized by the sol-gel method. Materials 11, 2364-2375. doi: 10.3390/ma11122364

Chiu, Y. H., Chang, T. F. M., Chen, C. Y., Sone, M., and Hsu, Y. J. (2019). Mechanistic insights into photodegradation of organic dyes using heterostructure photocatalysts. Catalysts 9:430. doi: 10.3390/catal9050430

Cun, W., Jincai, Z., Xinming, W., Bixian, M., Guoying, S., Ping'an, P., et al. (2002). Preparation, characterization and photocatalytic activity of nanosized $\mathrm{ZnO} / \mathrm{SnO}_{2}$ coupled photocatalysts. Appl. Catal. B Environ. 39, 269-279. doi: 10.1016/S0926-3373(02)00115-7

Dinh, C. T., Nguyen, T. D., Kleitz, F., and Do, T. O. (2012). A solvothermal single-step route towards shape-controlled titanium dioxide nanocrystals. Can. J. Chem. Eng. 90, 8-17. doi: 10.1002/cjce.20574

Ebrahimian, A., Monazzam, P., and Fakhari, B. (2017). Co/TiO 2 nanoparticles : preparation, characterization and its application for photocatalytic degradation of methylene blue. Desalin. Publ. 63, 283-292. doi: 10.5004/dwt.2017. 20205

Elbushra, H., Ahmed, M., Wardi, H., and Eassa, N. (2018). Synthesis and characterization of $\mathrm{TiO}_{2}$ using sol-gel method at different annealing temperature. MRS Advances. 3, 2527-2535. doi: 10.1557/adv.2018.23

Guettaï, N., and Ait Amar, H. (2005). Photocatalytic oxidation of methyl orange in presence of titanium dioxide in aqueous suspension. Part I: parametric study. Desalination 185, 427-437. doi: 10.1016/j.desal.2005.04.048

Haghighatmamaghani, A., Haghighat, F., and Lee, C. (2018). Performance of various commercial $\mathrm{TiO}_{2}$ in photocatalytic degradation of a mixture of indoor air pollutants: effect of photocatalyst and operating parameters. Sci. Technol. Built Environ. 4731, 1-41. doi: 10.1080/23744731.2018.1556051

Haque, F. Z., Nandanwar, R., and Singh, P. (2017). Evaluating photodegradation properties of anatase and rutile $\mathrm{TiO}_{2}$ nanoparticles for organic compounds. Optik 128, 191-200. doi: 10.1016/j.ijleo.2016.10.025
Grant Scheme (R.J130000.7854.5F242) and Collaborative Research Grant (R.J130000.7354.4B502), Research Grant from Nippon Sheet Glass Foundation for Materials Science and Engineering (R.J130000.7354.4B515) and Universiti Teknologi Malaysia for Industry-International Incentive Grant (Q.J130000.3654.02M62). A great appreciation to Tertiary Education Trust Fund-Nigeria (TET Fund) for doctoral study support and Faculty of Science, Universiti Teknologi Malaysia for the research facilities.

Hejazi, S., Mohajernia, S., Osuagwu, B., Zoppellaro, G., Andryskova, P., Tomanec, O., et al. (2020). On the controlled loading of single platinum atoms as a cocatalyst on $\mathrm{TiO}_{2}$ anatase for optimized photocatalytic $\mathrm{H} 2$ generation. Advan. Mater. 32:1908505. doi: 10.1002/adma.201908505

Hiremath, S., Antony Raj, M. A. L., Chandra Prabha, M. N., and Vidya, C. (2018). Tamarindus indica mediated biosynthesis of nano $\mathrm{TiO}_{2}$ and its application in photocatalytic degradation of Titan yellow. J. Environ. Chem. Eng. 6, 73387346. doi: 10.1016/j.jece.2018.08.052

Kang, X., Liu, S., Dai, Z., He, Y., Song, X., and Tan, Z. (2019). Titanium dioxide: from engineering to applications. Catalysts 9, 191-223. doi: $10.3390 /$ catal9020191

Kankara, S. S., Ibrahim, M. H., Mustafa, M., and Go, R. (2015). Ethnobotanical survey of medicinal plants used for traditional maternal healthcare in Katsina state, Nigeria. S. Afr. J. Bot. 97, 165-175. doi: 10.1016/j.sajb.2015.01.007

Khalik, W. F., Ong, S. A., Ho, L. N., Voon, C. H., Wong, Y. S., Yusoff, N. A., et al. (2017). Comparison the performance of carbon plate and Pt-loaded carbon in photocatalytic fuel cell (PFC) process. AIP Conf. Proceed. 1828:020014. doi: $10.1063 / 1.4979385$

Khataee, A. R., and Mirzajani, O. (2010). UV/peroxydisulfate oxidation of C. I. Basic Blue 3: modeling of key factors by artificial neural network. Desalination 251, 64-69. doi: 10.1016/j.desal.2009.09.142

Khataee, A. R., Pons, M. N., and Zahraa, O. (2010). Photocatalytic decolorisation and mineralisation of orange dyes on immobilised titanium dioxide nanoparticles. Water Sci. Technol. 62, 1112-1120. doi: 10.2166/wst.2010.438

Kim, T. H., Go, G. M., Cho, H. B., Song, Y., Lee, C. G., and Choa, Y. H. (2018) A novel synthetic method for $\mathrm{N}$ doped $\mathrm{TiO}_{2}$ nanoparticles through plasmaassisted electrolysis and photocatalytic activity in the visible region. Front. Chem. 6, 1-10. doi: 10.3389/fchem.2018.00458

Kitamura, Y., Okinaka, N., Shibayama, T., Mahaney, O. O. P., Kusano, D., Ohtani, B., et al. (2007). Combustion synthesis of $\mathrm{TiO}_{2}$ nanoparticles as photocatalyst. Powder Technol. 176, 93-98. doi: 10.1016/j.powtec.2007.02.009

Laoufi, N. A., and Bentahar, F. (2014). Pesticide removal from water suspension by $\mathrm{UV} / \mathrm{TiO}_{2}$ process : a parametric study. Desalin. Water Treat. 52, 1947-1955. doi: 10.1080/19443994.2013.804453

Lee, H., Song, M. Y., Jurng, J., and Park, Y. K. (2011). The synthesis and coating process of $\mathrm{TiO}_{2}$ nanoparticles using CVD process. Powder Technol. 214, 64-68. doi: 10.1016/j.powtec.2011.07.036

Li, Y., Fu, Y., and Zhu, M. (2019). Green synthesis of 3D tripyramid $\mathrm{TiO}_{2}$ architectures with assistance of aloe extracts for highly efficient photocatalytic degradation of antibiotic ciprofloxacin. Appl.Catal. B Environ. 260, 1-9. doi: 10.1016/j.apcatb.2019.118149

Lima, F. M., Martins, F. M., Herbert, P., Maia, F., Fabíola, A., Almeida, L., et al. (2018). Nanostructured titanium dioxide average size from alternative analysis of Scherrer' s. Rev. Mat. 23, 1-10. doi: 10.1590/s1517-707620170001.0301

Liu, F., Lu, L., Xiao, P., He, H., Qiao, L., and Zhang, Y. (2012). Effect of oxygen vacancies on photocatalytic efficiency of $\mathrm{TiO}_{2}$ nanotubes aggregation. Bull. Korean Chem. Soc. 33, 2255-2259. doi: 10.5012/bkcs.2012.33.7.2255

Ljubas, D., Smoljanić, G., and Juretić, H. (2015). Degradation of methyl orange and congo red dyes by using $\mathrm{TiO}_{2}$ nanoparticles activated by the solar and the solar-like radiation. J. Environ. Manage. 161, 83-91. doi: 10.1016/j.jenvman.2015.06.042

Luan, J., Chen, M., and Hu, W. (2014). Synthesis, characterization and photocatalytic activity of new photocatalyst $\mathrm{ZnBiSbO}_{4}$ under visible light irradiation. Int. J. Mol. Sci. 15, 9459-9480. doi: 10.3390/ijms15069459 
Marinescu, C., and Sofronia, A. (2011). DSC investigation of nanocrystalline $\mathrm{TiO}_{2}$ powder. J. Therm. Anal. Calorim. 103, 49-57. doi: 10.1007/s10973-010-1072-6

May-Masnou, A., Soler, L., Torras, M., Salles, P., Llorca, J., and Roig, A. (2018). Fast and simple microwave synthesis of $\mathrm{TiO}_{2} / \mathrm{Au}$ nanoparticles for gas-phase photocatalytic hydrogen generation. Front. Chem. 6, 1-13. doi: 10.3389/fchem.2018.00110

Mohamad, N. A. N., Arham, N. A., Jai, J., and Hadi, A. (2014). Plant extract as reducing agent in synthesis of metallic nanoparticles: a review. Advan. Mater. Res. 832, 350-355. doi: 10.4028/www.scientific.net/AMR.832.350

Murugan, R., and Parimelazhagan, T. (2014). Comparative evaluation of different extraction methods for antioxidant and anti-inflammatory properties from Osbeckia parvifolia Arn.-an in vitro approach. J. King Saud Univ. 26, 267-275. doi: 10.1016/j.jksus.2013.09.006

Órdenes-Aenishanslins, N. A., Saona, L. A., Durán-Toro, V. M., Monrás, J. P., Bravo, D. M., and Pérez-Donoso, J. M. (2014). Use of titanium dioxide nanoparticles biosynthesized by Bacillus mycoides in quantum dot sensitized solar cells. Microb. Cell Fac. 13:90. doi: 10.1186/s12934-014-0090-7

Parida, K. M., Pany, S., and Naik, B. (2013). Green synthesis of fibrous hierarchical meso-macroporous $\mathrm{N}$ doped $\mathrm{TiO}_{2}$ nanophotocatalyst with enhanced photocatalytic H2 production. Int. J. Hydrog. Energy 38, 3545-3553. doi: 10.1016/j.ijhydene.2012.12.118

Patel, D. K. (2015). Plants as a source of medicine. Med. Aromat. Plants S3:2167. doi: 10.4172/2167-0412.S3-e001

Phuinthiang, P., and Kajitvichyanukul, P. (2019). Degradation of paraquat from contaminated water using green $\mathrm{TiO}_{2}$ nanoparticles synthesized from Coffea arabica L. in photocatalytic process. Water Sci. Technol. 79, 905-910. doi: $10.2166 /$ wst.2018.493

Pintana, P., and Tippayawong, N. (2013). Nonisothermal thermogravimetric analysis of Thai Lignite with high $\mathrm{CaO}$ content. Sci. World J. 2013, 1-7. doi: 10.1155/2013/216975

Rab, N., Chong, F. K., Mohamed, H. I., and Lim, W. H. (2018). Preparation of $\mathrm{TiO}_{2}$ nanoparticles by hydrolysis of $\mathrm{TiCl} 4$ using water and glycerol solvent system. J. Phys. Conf. Ser. 1123, 1-8. doi: 10.1088/1742-6596/1123/1/012065

Raghad, D. H., Abdul, J., Nuaman, R. S., and Abd, A. N. (2016). Biological synthesis of titanium dioxide nanoparticles by Curcuma longa plant extract and study its biological properties. World Sci. News 49, 204-222. Available online at: www. worldscientificnews.com

Samkeliso, T., Fanyana, M., and Michael, P. (2018). Analysis of the phytochemical contents and antioxidant activities of crude extracts from Tulbaghia species. J. Tradit. Chin. Med. 38, 272-729. doi: 10.1016/j.jtcm.2018.04.005

Selvaraj, M. R., Bharathia, A., Prabhakarn, A., Abdul Rahuman, A., Velayutham, K., Rajakumar, G., et al. (2012). Efficient phytosynthesis and structural characterization of rutile $\mathrm{TiO}_{2}$ nanoparticles using Annona squamosa peel extract. Spectrochim. Acta A Mol. Biomol. Spectrosc. 98, 86-90. doi: 10.1016/j.saa.2012.08.055

Sethy, N. K., Arif, Z., Mishra, P. K., and Kumar, P. (2020). Green synthesis of $\mathrm{TiO}_{2}$ nanoparticles from Syzygium cumini extract for photo-catalytic removal of lead $(\mathrm{Pb})$ in explosive industrial wastewater. De Gruyter 9, 171-181. doi: 10.1515/gps-2020-0018

Solano, R. A., Herrera, A. P., Maestre, D., and Cremades, A. (2019). Fe$\mathrm{TiO}_{2}$ nanoparticles synthesized by green chemistry for potential application in waste water photocatalytic treatment. J. Nanotechnol. 2019, 1-11. doi: $10.1155 / 2019 / 4571848$

Sotubo, S. E., Lawal, O. A., Osunsami, A. A., and Ogunwande, I. A. (2016). Constituents and insecticidal activity of Deinbollia pinnata essential oil. Nat. Prod. Commun. 11:1889. doi: 10.1177/1934578x1601101228

Sundrarajan, M., Bama, K., Bhavani, M., Jegatheeswaran, S., Ambika, S., Sangili, A., et al. (2017). Obtaining titanium dioxide nanoparticles with spherical shape and antimicrobial properties using M. citrifolia leaves extract by hydrothermal method. J. Photochem Photobiol. B Biol. 171, 117-124. doi: 10.1016/j.jphotobiol.2017.05.003

Tan, Y. H., Davisa, J. A., Fujikawaa, K., Ganesh, N. V., Demchenko, A. V., and Stine, K. J. (2012). Surface area and pore size characteristics of nanoporous gold subjected to thermal, mechanical, or surface modification studied using gas adsorption isotherms, cyclic voltammetry, thermogravimetric analysis, and scanning electron microscopy. J. Mater.Chem. 22, 6733-6745. doi: 10.1039/c2jm16633j

Thakur, B. K., Kumar, A., and Kumar, D. (2019). Green synthesis of titanium dioxide nanoparticles using Azadirachta indica leaf extract and evaluation of their antibacterial activity. S. Afr. J. Bot. 124, 223-227. doi: 10.1016/j.sajb.2019.05.024

Venugopal, K., Ahmad, H., Manikandan, E., Thanigai Arul, K., Kavitha, K., Moodley, M. K., et al. (2017). The impact of anticancer activity upon beta vulgaris extract mediated biosynthesized silver nanoparticles (Ag-NPs) against human breast (MCF-7), lung (A549) and pharynx (Hep-2) cancer cell lines. J. Photochem. Photobiol. B Biol. 173, 99-107. doi: 10.1016/j.jphotobiol.2017.05.031

Yang, C., Dong, W., Cui, G., Zhao, Y., Shi, X., and Xia, X. (2017). Highlyefficient photocatalytic degradation of methylene blue by PoPD-modified $\mathrm{TiO}_{2}$ nanocomposites due to effect of $\mathrm{TiO}_{2}$ with PoPD. Sci. Rep. 7, 1-12. doi: 10.1038/s41598-017-04398-x

Yin, W., Zhang, L., Wang, Z., Wang, T., Zhou, C., Selloni, A., et al. (2013). Electronic structure and photoabsorption of Ti3+ ions in reduced anatase and rutile $\mathrm{TiO}_{2}$. Physical Chem. Chem. Phys. 1, 1-9. doi: 10.1039/c8cp02648c

Youssef, N. A., Shaban, S. A., Ibrahim, F. A., and Mahmoud, A. S. (2016). Degradation of methyl orange using Fenton catalytic reaction. Egypt. J. Pet. 25, 317-321. doi: 10.1016/j.ejpe.2015.07.017

Zakrzewska, K., and Radecka, M. (2017). $\mathrm{TiO}_{2}$-based nanomaterials for gas sensing- influence of anatase and rutile contributions. Nanoscale Res. Lett. 12, 1-8. doi: 10.1186/s11671-017-1875-5

Conflict of Interest: The authors declare that the research was conducted in the absence of any commercial or financial relationships that could be construed as a potential conflict of interest.

Copyright (C) 2020 Rufai, Chandren and Basar. This is an open-access article distributed under the terms of the Creative Commons Attribution License (CC BY). The use, distribution or reproduction in other forums is permitted, provided the original author(s) and the copyright owner(s) are credited and that the original publication in this journal is cited, in accordance with accepted academic practice. No use, distribution or reproduction is permitted which does not comply with these terms. 